\title{
Proposal of a local telemetry network for the monitoring the thermodynamic and environmental performances of farm tractors
}

\author{
Fabrizio Mazzetto, Marco Bietresato \\ Free University of Bozen-Bolzano, Faculty of Science and Technology - Fa.S.T., Bolzano, Italy
}

\section{Abstract}

The TRAKTnet.one project aims to identify and develop new solutions to remotely monitor the efficiency of farm-tractors engines included in a local voluntary network. The knowledge of tractors' efficiency can give important information concerning machines' consumption, emissions and need for servicing, thus contributing to a more environmentally-sustainable agriculture. Engines will be monitored by measuring rpms, exhaust gas temperature and oxygen content (through lambda sensors) and then analysing and inferring the data through procedures, which algorithms will be an integral part of the project's results.

Trials will be performed on different engines and at different speeds/loads. The choice of the thermocouple type and installation point must be done carefully for not influencing sensitivity and response time. The final outcome of the project is expected to be an automatic system, based on an inference software-engine able to correctly interpreting the sensors outputs. The advantage of this proposal is to exploit a farm monitoring network, previously designed for managing the information related to the automatic compilation of records in the country, by simply equipping data loggers with two additional sensors.

Correspondence: Marco Bietresato, Free University of Bozen-Bolzano, Faculty of Science and Technology - Fa.S.T., piazza Università 5, P.O. Box 276, I-39100 Bolzano (BZ), Italy.

Tel. +39.0471 .017181 - Fax: +39.0471 .017009 .

E-mail:marco.bietresato@unibz.it

Key words: Farm tractors; engine performances; remote monitoring; telemetry.

Acknowledgements: the authors wish to thanks Dr. Aldo Calcante of Università degli Studi di Milano and Dr. Carlo Bisaglia of CRA-ING for their assistance during the experimental surveys at the test bench.

Conflict of interests: the authors declare no potential conflict of interests.

Conference presentation: this paper has been submitted to The Italian Society of Agricultural Engineering for the 10th AIIA Conference "AIIA13 Horizons in agricultural, forestry and biosystems engineering", which will be held in Viterbo, University of Tuscia, Italy, on September 8-12, 2013.

(C) Copyright F. Mazzetto and M. Bietresato, 2013

Licensee PAGEPress, Italy

Journal of Agricultural Engineering 2013; XLIV(s2):e25

doi:10.4081/jae.2013.s2.e25

This article is distributed under the terms of the Creative Commons Attribution Noncommercial License (by-nc 3.0) which permits any noncommercial use, distribution, and reproduction in any medium, provided the original author(s) and source are credited.

\section{Introduction}

\section{General considerations and problem description}

The necessary condition for developing a sustainable agriculture is to raise the overall efficiency of farm machines by: (1) increasing their annual exploitation, (2) keeping constant their performance over the time. This intensive control on machines must necessarily imply: (a) the implementation of a Farm-Information-System (FIS) based on a client-server approach, to acquire and manage information needed for taking decisions at both farm and territorial scale, through a FarmOperational-Monitoring, using telemetry and data-loggers on tractors and implements (Mazzetto, Calcante, \& Salomoni, 2009; Sahu \& Raheman, 2008; Yule, Kohnen, \& Nowak, 1999), (b) the proposal of solutions that are economical, simple, robust, reliable and effective in acquiring selected engine parameters (Singh \& Singh, 2011).

The TRAKTnet.one project of the Free University of Bolzano aims to identify and develop new solutions to remotely control the efficiency (hence: consumption, emissions and need for servicing) of farm-tractors engines included in a local voluntary network all along their lifespan, thus contributing to a more environmentally-sustainable agriculture. The proposed solutions will be based on remote measurements of exhaust gases' temperature (De Souza \& Milanez, 1987; Friso, 1988; Pang, Zoerb, \& Wang, 1985) and oxygen; these parameters will be analysed and inferred through procedures, which algorithms will be an integral part of the project's results.

Several experiences reported in literature (Friso, 1988; Goering, Hansen, Lyne, \& Meiring, 1986) show that the EG temperature is proportional to the engine torque, thus allowing for an indirect calculation of engine load and related instant power (this is possible only knowing a priori the maximum rated power each engine can provide). The combustion quality, on the other hand, can be related to the oxygen concentration in the EGs, measured through lambda sensors, thus enabling a rough estimate of the engine efficiency.

Engines will be monitored by measuring rpms, EGs' temperature and oxygen content (as indexes indirectly estimating consumption and efficiency) and then analysing and inferring the data through procedures, which algorithms will be an integral part of the project's results (Alvarez \& Huet, 2008). This implies: (1) the existence of a service centre controlling all farm machines and managing a FIS network through simple logical connections according to a client-server approach, (2) a database relative to all the monitored engines when they are new, in order to have a comparison term with the data collected by the network. This database will be compiled starting from the data reported on the OECD test reports and from properly tuned numerical models, without any additional test to be performed during the type-testing of a tractor.

\section{Aim of the research}

The final outcome of the project is expected to be an automatic system, based on an inference software-engine able to correctly interpreting the sensors' outputs. It could be used by tractors' owners for being 
advised about the need for servicing their vehicles but also by local authorities for monitoring tractors' environmental impact in a territory and, maybe, for tailoring the subsidies to the farmers (e.g., on a rewarding-score in accordance to the detected performances).

The advantage of this proposal is to exploit a farm monitoring network, previously designed for managing the information related to the automatic compilation of records in the country, by simply equipping data loggers with additional sensors.

\section{Materials and Methods}

\section{System definition and implementation}

The system and its components at every level have been defined by using a top-down approach, hence, after formulating the general task(s) of the system, its main elements (i.e., the first-level subsystems) have been specified but not detailed. The detailed refinement of each subsystem is the final task and will be afforded afterwards.

The system general architecture has been defined starting from the following needs/technical requirements:

- collecting a series of data on vehicles operating in an environment presenting several potential problems for electronic devices (e.g., humidity, dust, heat sources);

- $\quad$ interpreting the collected data to obtain therefore information concerning the functioning of farm engines;

- putting this information at the disposal of the farmers and/or local authorities.

After defining the architecture, four steps will be followed: (1) preliminary assessment of sensors features (e.g., number, type, position); (2) numeric modelling of a compression-ignition engine to understand the effects of ageing and bad maintenance on its performances; (3) evaluation of possible modifications of commercial sensors (e.g., K- or J-type thermocouples, zirconium-oxide lambda sensor); (4) execution of bench and field tests to validate the system.

The choice of the thermocouple type (band/rod) and installation point (manifold/pipe) must be done carefully for not influencing sensor's sensitivity and response time. The combustion quality can be related to the oxygen concentration in exhaust gases (EG). Trials will be performed on different engines (e.g., naturally-aspired/turbocharged, with/without EGR/SCR or analogous devices) and at different speeds/loads (full load, partial loads, idle).

\section{Preliminary bench tests}

Some preliminary bench tests were carried out at the CRA-ING OECD laboratory centre (Treviglio, BG, Italy) with the aim of finding the best position for recording the EG temperature. The tests concerned three farm tractors covering a wide range of powers and engines types (Table 1). The experimental procedure consisted of several bench tests (163 trials in total, 48-60 per tractor) aimed to record engines' performances (instant torque, power and brake specific fuel consumption-BSFC) and the relative EG temperatures in their operating ranges (Jahns et al., 1990); each test started only after the engine warmed up and included:

- a classic OECD bench test with the fuel-pump rack fully-opened;

- other four tests with the fuel-pump rack at intermediate positions between the maximum and the minimum (each spaced approximately of $200 \mathrm{rpm}$ ).

During the tests, three thermocouples were used to measure the EG temperature in three different points of the exhaust pipeline:

- one mineral-insulated $K$-type thermocouple, with its tip inserted inside the exhaust manifold (in direct contact with the gas) and fixed to the manifold through a bayonet coupling ( $\rightarrow$ temperature measured with this thermocouple: TcK);

- two J-type thermocouples, fixed through hose clamps respectively in contact with the second cylinder's exhaust pipe ( $\rightarrow$ temperature: TcJ-cyl) and outside of the exhaust manifold ( $\rightarrow$ temperature: TcJ).

EGs' temperature was sampled only after 5 minutes the engine was subjected to a set brake force (time interval tuned after the first surveys) to have a stable value of the temperature for each operating condition.

The Response Surface Modelling-RSM (Maheshwari et al., 2011) was used to study the test results. Previous works (Friso, 1988; Goering et $a l ., 1986)$ showed that the relationship existing between torque- $M$, engine speed- $n$ and EG temperature- $T$ can be numerically approximated by third-degree full-cubic polynomials. If $y_{k}$ and $x_{i, k}$, are, respectively, the $k$-th predicted value of a generic response and the corresponding values of the $x_{i}(i=1,2)$ generic factors, i.e. independent variables, noncoded, $a_{0}$ is the interception coefficient, $a_{i}, a_{i i}, a_{i i i}, a_{i j}$ and $a_{i j h}(i \neq j \neq h)$ are the coefficients of the linear, quadratic, cubic, $2^{\text {nd }}-$ order and $3^{\text {rd }}$ order interaction terms, the generic regression model used in RSM is:

$$
y_{k}\left(x_{i} ; i=1,2\right)=a_{0}+\sum_{i=1}^{2} a_{i} x_{i, k}+\sum_{1 \leq i \leq j \leq 2} a_{i j} x_{i, k} x_{j, k}+\sum_{1 \leq i s j \leq h \leq 2} a_{i j h} x_{i, k} x_{j, k} x_{h, k}
$$

Design-Expert 7.0.0 (Stat-Ease, Minneapolis, MN, USA) was used to analyse the collected data and propose for each response a regression model with only the significant terms (ANOVARSM; the terms have been chosen according to RSM-software suggestions).

Table 1. Tractors' engine main specifications.

\begin{tabular}{lllll} 
Engine technical characteristic & Unit & Same Explorer 70 DT & $\begin{array}{l}\text { Farm tractor } \\
\text { Same Explorer 80 DT }\end{array}$ & Same Laser 130 DT \\
\hline Manufacturer/type & - & Same, 1000.4 A & Same, 1000.4 Al & Same, 1056 P \\
Cylinders/configuration & $\mathrm{nr}$. & 4, straight & 4, straight & 6, straight \\
\hline Piston bore/stroke & $\mathrm{mm}, \mathrm{mm}$ & $105.0,115.5$ & $105.0,115.5$ & $105.0,120.0$ \\
Compression ratio & - & 17.1 & 17.1 & n.a. \\
\hline Total displacement & $\mathrm{cm}^{3}$ & 4000 & 4000 & 6234 \\
Max power value/engine speed & $\mathrm{kW}, \mathrm{rpm}$ & $47.07 @ 2350$ & $54.20 @ 2509$ & $92.00 @ 2260$ \\
\hline Engine speed range & $\mathrm{rpm}$ & $675-2509$ & $700-2712$ & n.a. \\
\hline
\end{tabular}

n.a.: not available data 


\section{First model of the engine}

With the aim of calculating the EG temperature of the new engine of each model of tractor connected in the network, a numerical/analytical model should be created with a certain degree of detail from the OECD test report's data. In this case, the analyst has a great freedom in how creating the engine model, in the achievable level of detail and in the choice of the software to be used. In fact, he may:

- implement a series of thermodynamic transformations (more or less ideal) using equations directly written within a program; the software used in this case can even have a purely textual interface (e.g., Microsoft Visual Basic; Mathworks Matlab);

- approach the problem through precompiled or writable function blocks, properly connected to each other to describe exchanges of matter, energy or information, graphically building a layout similar to the real one; the suitable software have a graphical interface and adopt a single-port (e.g., Mathworks Simulink) or a multi-port icons description (e.g., Gamma Technologies GT-Power, LMS Imagine.Lab AMESim);

- opt for a multi-dimensional simulative approach (2D, 2D axially-symmetric, 3D) adopting a discretization of the domain (finite element method, geometric element method, boundary element method) useful in the detail modelling of the heat transfer phenomena.

The software used for the creation of the first models is AMESim 12.0.0 (LMS Imagine, Leuven, Belgium). In AMESim each individual element/component is associated to a subroutine whose inputs can be entered by the user or come from other elements/components. The exchange quantities for each block are written in terms of power (Bond-Graph approach) and therefore are always expressed as a scalar product of two vector quantities. The used elements are zero- or onedimensional, require limited computational times and give in the meantime the possibility of simulating also very complex systems (e.g. a complete engine). AMESim uses a lumped and distributed parameter approach in which the necessary ordinary (for 0D-elements) or partial (for 1D-elements) differential equations of the system are automatically written by the software.

\section{Results}

\section{System components}

The monitoring system is composed of three basic elements (Figure 1 left):

- hardware devices, for collecting and/or storing the data (sensors, data logger with communication capabilities, servers with storage units);
- a set of automatic computing procedures, based on several physical models of the engines (one model per each engine) to obtain timerelated information about the engine performances from the raw data achieved; the output formats can be both tabular and graphical; - interfaces, to enable the users the access and use of the information.

The system presented here will be fully interfaced with a FIS (Mazzetto et al., 2009) and can be seen as completion of it: some important data collected by the farm monitoring network (e.g., concerning field operations), will be related to the acquisitions of additional sensors on engines, thus extending the FIS monitoring also to all the involved power units. In particular, the field-event data-logger (FDL), already present on board all the vehicles connected in a FIS network, will be completed of the following components, connected to its input and output ports (Figure 1 right):

- two/three input units, i.e. an engine speed sensor, an EG temperature sensor (thermocouple) and, eventually, also a zirconium-oxide lambda sensor;

- $\quad$ one/two output unit(s), i.e. a GPRS antenna and, eventually, a liquid crystals display positioned on the tractor's dashboard.

The FDL, powered by the 12-V-DC electrical system of the tractor, is the kernel of the on-board system and has several functions:

- it is necessary for the power supply of all the connected $\mathrm{I} / 0$ units, which are typically passive, i.e. not powered independently;

- it collects and stores temporarily the data collected by the sensors, providing to send the raw data (or the interpreted data; see below) to a remote server via GPRS;

- if provided with the correct calibration curves, it is capable to interpret directly the sensors' analogue/digital signals as physical quantities (engine speed, EG temperature, EG oxygen concentration) before sending them to a server.

\section{System conceptual functioning}

The system operates conceptually in three different phases: - usage of the OECD test results for tuning a physical model of the
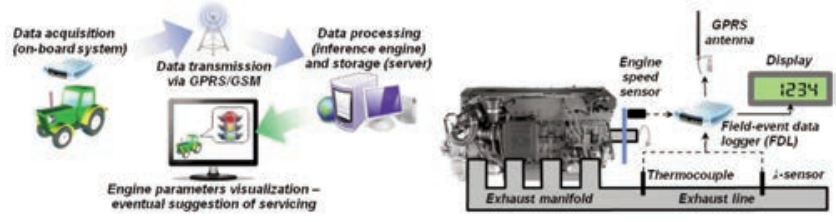

Figure 1. (left) general functioning of the monitoring system for the tractors; (right) on-board components involved in the engine monitoring (dashed/continuous arrows indicate raw/interpreted data flows; powersupply connections are not represented).

Table 2. Main results of bench tests and RSM analyses (M: torque; P: power; S: speed; T: temperature).

\begin{tabular}{|c|c|c|c|c|c|c|c|c|c|c|}
\hline \multirow[t]{2}{*}{ Tr. } & \multirow{2}{*}{$\begin{array}{c}\text { Operating } \\
\text { point }\end{array}$} & \multicolumn{5}{|c|}{ Experimental measurements } & \multicolumn{4}{|c|}{$\mathrm{R}^{2}$ of $T=f(M, S)$ fitting } \\
\hline & & $\mathrm{M}(\mathrm{Nm})$ & $\mathrm{P}(\mathrm{kW})$ & S (rpm) & TcK (K) & $\mathrm{TeJ}(\mathrm{K})$ & TcJ-cyl (K) & TcK & $\mathrm{TeJ}$ & TcJ-cyl \\
\hline \multirow[t]{3}{*}{ SAME 70} & Idle & - & - & 221 & 377 & 336 & 318 & 0.9986 & 0.9968 & 0.9691 \\
\hline & $\operatorname{Max} P$ & 423 & 45 & 1024 & 832 & 449 & 320 & & & \\
\hline & Max M & 548 & 34 & 588 & 832 & 492 & 336 & & & \\
\hline \multirow[t]{3}{*}{ SAME 80} & Idle & - & - & 381 & 413 & 357 & 342 & 0.9960 & 0.9889 & 0.9344 \\
\hline & Max P & 465 & 47 & 956 & 880 & 449 & 346 & & & \\
\hline & Max M & 582 & 37 & 613 & 855 & 472 & 356 & & & \\
\hline \multirow[t]{3}{*}{ SAME 130} & Idle & - & - & 325 & 393 & 407 & 342 & 0.9966 & 0.9738 & 0.9799 \\
\hline & $\operatorname{Max} P$ & 804 & 84 & 995 & 981 & 594 & 462 & & & \\
\hline & Max M & 913 & 55 & 572 & 923 & 612 & 490 & & & \\
\hline
\end{tabular}


engine; usage of the tuned physical model for correlating the EG temperature and the specific consumption/efficiency with the torque and the speed, thus developing some mathematical models with different degrees of detail/complexity (Figure 2);

- usage of the temperature data, recorded during the normal operating of a tractor, together with the time history of field operations recorded through the FDL for correlating together torque, speed and efficiency of a model of tractor with some hours of operation (Yule et al. 1999; Kolator and Białobrzewski, 2011); integration of this model into the main FDL inference engine to have an estimate of the engine torque or efficiency;

- comparison of the efficiency values predicted by the two models to quantify the performance decrement of the engine (Alvarez and Huet, 2008) and suggestion to the driver of eventual extraordinary maintenance interventions to the vehicle.

RSM will be used in the first phase (Figure 2) and in particular in two different sub-phases:

- to approximate the equations of torque, power, BSFC and efficiency as a function of the engine speed, starting from standard OECD test results (full-load curve, part-loads curves at rated engine speed and at PTO speed);

- to build 2-variable models of the EG temperature and engine efficiency as a function of torque and engine speed from the output data coming from a tuned physical model of the engine.

\section{Positioning of the EG thermocouple}

The bench tests and the subsequent RSM confirmed the experiences reported in literature, showing that, for a set engine speed, the EG temperature $T$ is positively correlated with the torque $M\left(\mathrm{R}^{2} \geq 0.9344\right.$; Figure 3 ; Table 2). The K-thermocouple gave the most statistically-significant measurements (best $\mathrm{R}^{2}$ ) and had the higher instrumental sensitivity (or "gain", here: $\partial \mathrm{T} / \partial \mathrm{M})$ in the engine torque range $\left(\Delta \mathrm{T}_{\mathrm{TcK}} \geq 450^{\circ} \mathrm{C}\right.$, i.e. more than 3 times $\Delta \mathrm{T}_{\text {TcJ }}$ and up to 34 times $\Delta \mathrm{T}_{\text {TcJ-cyl }}$ during the same tests), surely due to the absence of an interposed (pipe's) material, having an its own inertia and thermal conductivity.

\section{Engine model}

The first developed model reproduces the layout of a hypothetical single-cylinder Diesel engine. It has the same geometric-functional characteristics of a single cylinder of SAME Explorer 70's engine (obtained from the OECD test report and by modelling the piston; Figure 4).

The model layout includes also the intake and the exhaust systems (respectively: from the air filter to the motor, from the motor to the exhaust pipe; Figure 5).

This model uses:

- 67 input parameters (geometrical, thermodynamic, functional) entered by the user, deduced from the OECD test report's data directly or indirectly (with the aid of a spread sheet)

- The Barba combustion model (dual-zone, specific for Diesel engines)

- The Annand model for the gases-combustion chamber's walls heat exchange, with the value of the convection and radiation coefficients taken from the software library

- The values of the properties of fuel and metallic materials of the intake and exhaust pipes, of the convective and radiative coefficients taken from the software library

- The values of direct and inverse flow coefficients through the valves, valves lift function, IVO and EVC angles, injection map, injector flow profile and nozzle sizes taken from the software library

After simulating 10 seconds of engine operation at 2350 -rpm rotational speed (i.e., 196 cycles), the torque stabilizes at $56.03 \mathrm{Nm}$, corre-

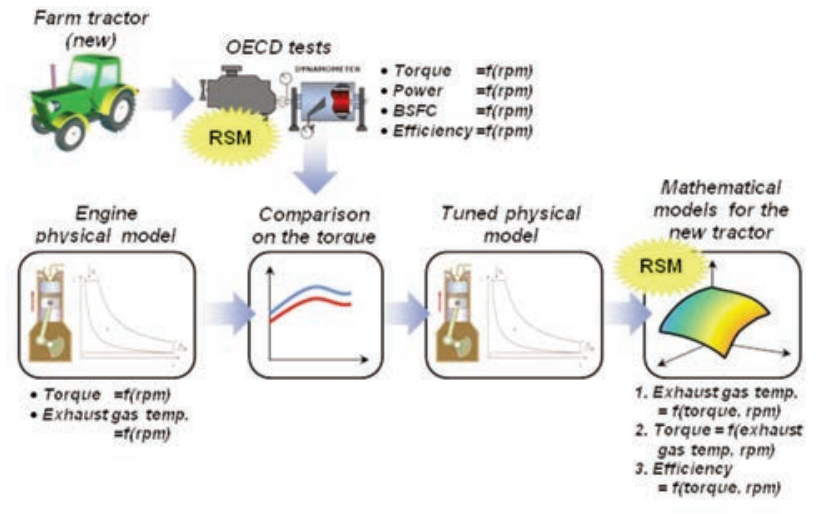

Figure 2. First phase of the conceptual functioning of the system, concerning the modelling of a new engine; in evidence the sub-phases in which Response Surface Modelling (RSM) can be used.
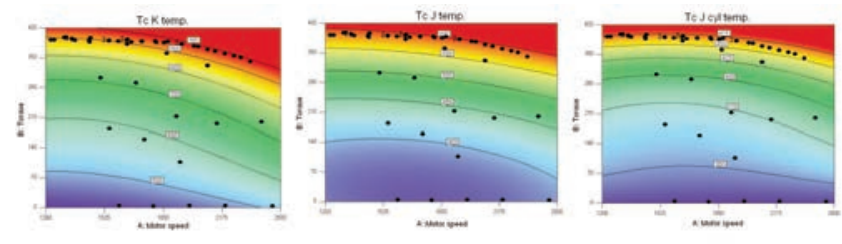

Figure 3. Contour plots of the temperatures regression models for Same

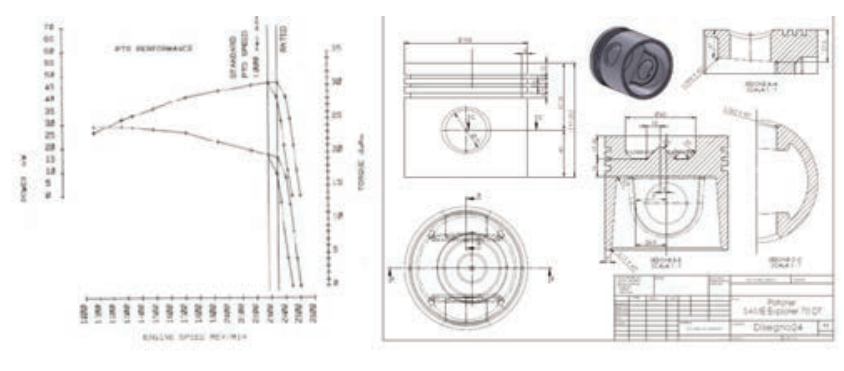

Figure 4. SAME Explorer 70's characteristic curves (left; source: OECD test report) and piston (right).

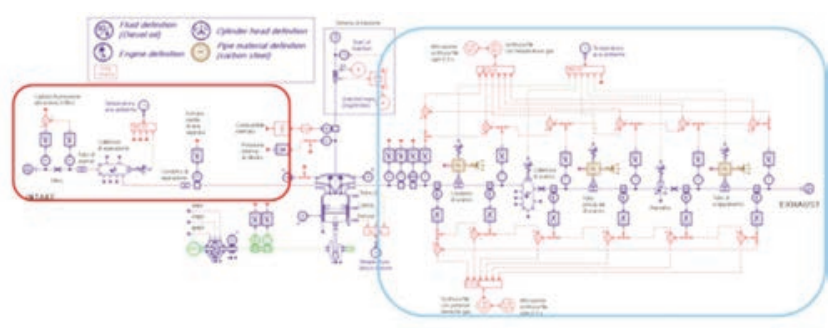

Figure 5. Layout of the model of a tractor engine, complete of the intake (red) and exhaust (blue) pipelines. 
sponding to a power of $13.79 \mathrm{~kW}$, net of any frictional loss. The OECD power value is $47.07 \mathrm{~kW}$, therefore $15 \%$ lower than the value $(55.16 \mathrm{~kW})$ obtainable by simply multiplying by 4 (number of engine's cylinders) the value obtained above. Although the multiplication of the singlecylinder engine output to have the output of a similar multiple-cylinder engine gives approximate results and the obtained difference is significant, this result is promising. In fact it should be considered that it was obtained with a not-yet tuned model and, especially, without taking into account any mechanical (engine, transmission) and viscous (fan) friction which are normally present in a real motor, and not considering the interactions between input and output gas flows that will surely exist in a multi-cylinder engine. The model gives the analyst the chance to have a graphical-numerical output of many physical quantities in several points of the layout (e.g., see Figure 6) ad in particular to check the EG temperature (Figure 7).

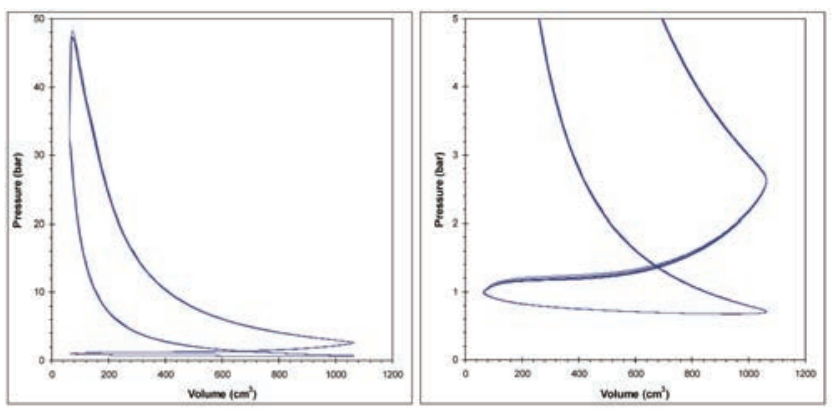

Figure 6. (left) Clapeyron diagram of the combustion chamber; (right) magnification of the passive part of the engine cycle in which inlet and outlet phases are visible.

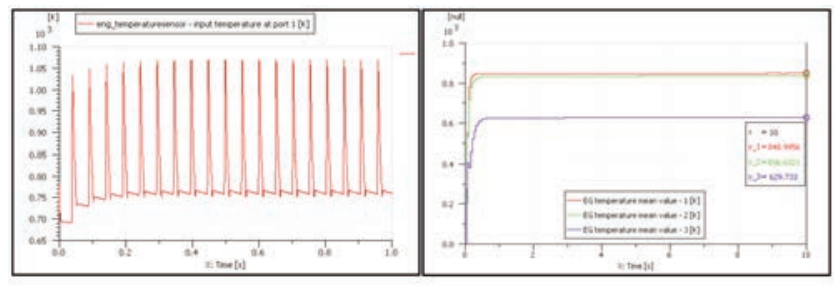

Figure 7. (left) instant EG temperature at the cylinder's outlet (first second); (right) EG mean temperature at three different points of the exhaust (cylinder's outlet; collector's outlet; muffler's outlet).

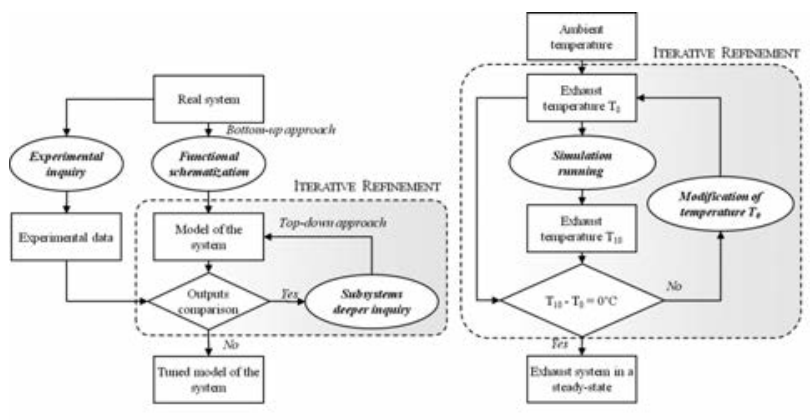

Figure 8. (left) process of system modelling and model calibration; (right) process of finding a steady-state operation for the exhaust system (T0: initial temperature; T10: temperature at $10 \mathrm{~s}$ ).

\section{Conclusions and future work}

Thanks to some preliminary bench tests, the correlation of the EG temperature with the torque and engine speed was fully confirmed and hence will be used in the project. Thinking about the monitoring system, the same tests were useful to realize that a thermocouple placed outside the exhaust manifold/pipe, although very easy to install, could be a feasible solution only if stating that the acquisitions can be taken after the engine keeps its speed constant for a certain period. As this situation could rarely happen during the normal operation of a tractor, and considering also the higher sensitivity shown by the thermocouple with the tip inside the exhaust line, this latter solution revealed to be the best one to be applied in the tractors. A first numerical model of an engine shows the high potential of the used software (LMS Imagine.Lab AMESim): it can simulate real combustion and heat transmission phenomena and lets the user access to many physical quantities in every point of the layout. Notwithstanding the many assumptions done and without tuning the model, the torque output (calculated for four cylinders) differs only of $15 \%$ from OECD data. The next two phases will involve the completion of the model with other three cylinders and its subsequent calibration. The tuning will involve all those aspects for which there are no details/data (e.g., intake and exhaust ducts length, localized pressure losses, IVO and EVC values). A diagram of the (iterative) procedure for setting up a numerical model of an engine is visible in Figure 8 . The further phase will involve the reaching of a thermal steady-state for the exhaust system. Since it would be impossible to simulate 10 minutes of engine operation (11760 cycles at $2350 \mathrm{rpm} ; 60 \mathrm{~Gb}$ of hard disk occupancy), the initial temperature of the exhaust pipes' metal will be modified in order to have a constant temperature during the simulation time (10 s; Figure 8).

\section{References}

Alvarez, I., \& Huet, S. (2008). Automatic diagnosis of engine of agricultural tractors: The BED experiment. Biosystems Engineering, 100(3), 362369. doi:10.1016/j.biosystemseng.2008.04.003

De Souza, E. G., \& Milanez, L. F. (1987). Indirect evaluation of the torque of diesel engines. Transactions of the ASAE, 31(5), 1350-1354.

Friso, D. (1988). Modello matematico per l'ottenimento rapido del piano quotato dei consumi di un motore diesel [Mathematical model to obtain quickly the contour map of diesel engine specific fuel consumptions]. Rivista di Ingegneria Agraria, 1, 56-61.

Goering, C. E., Hansen, A. C., Lyne, P. W. L., \& Meiring, P. (1986). Model for predicting tractor engine performance. In International Symposium on Agricultural Engineering. Pretoria, South Africa.

Mazzetto, F., Calcante, A., \& Salomoni, F. (2009). Development and first tests of a farm monitoring system based on a client server technology. In Precision Agriculture '09. 7th European Conference on Precision Agriculture 2009 (pp. 389-396). Wageningen, The Netherlands.

Pang, S. N., Zoerb, G. C., \& Wang, G. (1985). Tractor monitor based on indirect fuel measurement. Transactions of the ASABE, 28(4), 994-998.

Sahu, R. K., \& Raheman, H. (2008). A decision support system on matching and field performance prediction of tractor-implement system. Computers and Electronics in Agriculture, 60(1), 76-86. doi:10.1016/j.compag.2007.07.001

Singh, C. D., \& Singh, R. C. (2011). Computerized instrumentation system for monitoring the tractor performance in the field. Journal of Terramechanics, 48(5), 333-338. doi:10.1016/j.jterra.2011.06.007

Yule, I. J., Kohnen, G., \& Nowak, M. (1999). A tractor performance monitor with DGPS capability. Computers and Electronics in Agriculture, 23(2), 155-174. doi:10.1016/S0168-1699(99)00029-0 